\title{
CONSCIÊNCIA E EXPERIÊNCIA: CONTRIBUIÇÕES PARA A FORMAÇÃO HUMANA
}

\author{
Juliano Boscatto, Universidade Federal de Santa Catarina - UFSC, Santa Catarina- \\ Brasil \\ Elenor Kunz, Universidade Federal de Santa Catarina - UFSC, Santa Catarina-Brasil
}

\section{RESUMO}

$\mathrm{Na}$ era contemporânea muito tem se discutido e divulgado na mídia a respeito de questões de relacionadas à conservação do meio ambiente. As relações entre os elementos culturais, da natureza e do corpo, historicamente contribuíram para a formação de uma sociedade com características extremamente funcionais. Com o domínio da natureza e do próprio ser humano, estruturam-se elementos culturais, nos quais objetiva-se atingir o máximo desempenho e "evolução" possível. Apresentar subsídios teóricos para a Educação Física, sob uma visão de ser humano compreendido na perspectiva de totalidade com os elementos da natureza e da sociedade, é objetivo deste estudo.

Palavras-Chave: Consciência; Experiência; Educação.

\section{CONSCIOUSNESS AND EXPERIENCE: CONTRIBUTIONS TO HUMAN DEVELOPMENT}

\begin{abstract}
In the contemporary era has been much discussed and publicized in the media about issues related to environmental conservation. The relations between cultural elements, nature and the body has historically contributed to the formation of a society with extremely functional features. With the domination of nature and human being, cultural elements are structured, where the objective is to achieve maximum performance and "evolution" as possible. Present theoretical support for Physical Education, under a vision of human being understood from the perspective of all the elements of nature and society, the objective of this study.
\end{abstract}

Key-Words: Consciousness; Experience; Education.

\section{CONCIENCIA Y LA EXPERIENCIA: CONTRIBUCIÓN AL DESARROLLO HUMANO}

\section{RESUMEN}

En la época contemporánea ha sido muy discutido y publicitado en los medios de comunicación sobre temas relacionados con la conservación del medio ambiente. Las 
relaciones entre los elementos de la cultura, la naturaleza y el cuerpo ha contribuido históricamente a la formación de una sociedad con características muy funcionales. Con la dominación de la naturaleza y el ser humano, los elementos culturales se estructuran, donde el objetivo es lograr el máximo rendimiento y la "evolución" como sea posible. Apoyo teórico actual de la Educación Física, bajo una visión del ser humano entendido desde la perspectiva de todos los elementos de la naturaleza y la sociedad, el objetivo de este estudio.

Palabras-Clave: Conciencia; Experiencia; Educación. 


\section{CONSIDERAÇÕES INICIAIS}

Com o advento do século XXI muito tem se discutido e, posteriormente divulgado através de diversos veículos de comunicação a respeito de questões de fundamental importância para a conservação ou reabilitação do meio ambiente. Estas informações transmitidas apontam para a tentativa de minimizar a poluição, bem como impedir o fim de espécies em extinção e dos recursos naturais, com o intuito de evitar maiores estragos ao planeta azul. Acompanham essas notícias também outras informações relevantes, as quais põem em destaque a expansão tecnológica e científica, que desencadearam em avanços na área da Biologia e da Medicina, no desenvolvimento da indústria espacial e da informática entre outros "progressos" obtidos por meio da aposta e crença na racionalidade humana. Os avanços científicos e tecnológicos amplamente divulgados e comercializados, por muitas vezes, tendem a justificar tamanha degradação ambiental.

Compreende-se que a sociedade contemporânea é produto de um processo em constante mutação e, historicamente se desenvolve através da interação entre os elementos: do corpo especificamente, da natureza - enquanto base para sobrevivência das espécies - e da cultura produzida pelos seres humanos. Santin ${ }^{1}$ destaca alguns "distanciamentos perversos" que certamente contribuíram para a formação do atual quadro sócioeconômico e ambiental. Entre os "distanciamentos" o autor destaca primeiramente o plano do corpo no qual: "O Homem se separa em duas partes". 1:65 Situa-se neste aspecto, a compreensão do dualismo cartesiano em que a antropologia ocidental traz a crença de que o homem é alma e corpo, mente e corpo, espírito e matéria, destacando-se a compreensão hierárquica dos aspectos cognitivos sobre os "corporais".

Outra instância de acordo com Santin ${ }^{1: 65 ~ “[. . .] ~ m a n i f e s t a-s e ~ n a ~ d i s t i n c ̧ a ̃ o ~ e ~ o p o s i c ̧ a ̃ o ~ e ~ n a ~}$ luta do homem contra a natureza". Neste âmbito ao homem é conferido o poder em dominar, neutralizar e explorar a natureza e seus recursos, por muitas vezes, de forma descontrolada em favor do progresso técnico-científico e econômico. E, por fim, é mencionado uma "[...] separação entre os homens dentro da ordem social". 1:65 Embora segundo a ordem da natureza todos pertencemos a uma mesma espécie, por longos períodos tratou-se de uma certa sobreposição entre os seres humanos dentro de um Conexões: revista da Faculdade de Educação Física da UNICAMP, Campinas, v. 10, n. 2, p. 34-48, maio/ago. 201236 ISSN: 1983-9030 
determinado contexto social, como por exemplo, patrão e empregado, capitão e soldado, técnico e atleta.

Estas relações entre os elementos da cultura, da natureza e do corpo, historicamente contribuíram para a formação de uma sociedade com características extremamente funcionais, ou seja, através do domínio da natureza e do próprio ser humano, estruturam-se elementos culturais, nos quais objetiva-se atingir o máximo desempenho e "evolução" possível. Este processo desenrola-se principalmente através do uso e da crença na capacidade racional utilizada com finalidades técnicas e instrumentais disciplinando assim, os corpos a serem adaptados e produtivos ao sistema sócioeconômico vigente.

A partir deste contexto, faz-se necessário inicialmente compreender de forma mais clara como se relacionam os elementos natureza, corpo humano e cultura, ou seja, compreender de que maneira estes aspectos constituem-se e, como se desenvolve a corporeidade. Neste âmbito, busca-se a compreensão de que a corporeidade, sobretudo se desenvolve nas relações entre o corpo que constitui-se paralelamente com a cultura, desenvolvendo-a continuamente, transformando e modificando a natureza. Neste sentido, que Freitas ${ }^{2: 53}$ assinala que:

O corpo humano, como corporeidade - como permanência que se constrói no emaranhado das relações sócio-históricas e que traz em si a marca individualidade - não termina nos limites que a anatomia e a fisiologia lhe impõem. Ao contrário, estende-se por meio da cultura, das roupas e dos instrumentos criados pelo homem. O corpo conferelhes um significado e sua utilização passa por um processo de aprendizagem de hábitos.

Assim, pode-se afirmar que o corpo humano e a natureza, ou seja, o ser humano e o mundo são vistos de forma indissociável constituindo-se mutuamente, na medida em que os sujeitos agem de forma intencional atribuindo sentidos e significados nas suas próprias ações intervindo assim no contexto sócio-cultural. 
Entretanto, historicamente esta concepção de corporeidade não prevalece nos contextos universitários ${ }^{1}$, nos currículos acadêmicos, bem como na formação de professores, refletindo este quadro também em âmbito escolar. Há uma supervalorização na tradição dualista em que se destaca um corpo "natural" fracionado que deve ser educado através do domínio sobre os instintos e as pulsões inatas para uma boa funcionalidade social. Louro $^{3: 60}$ destaca que "Todos os processos de escolarização sempre estiveram - e ainda estão - preocupados em vigiar, controlar, modelar, corrigir, construir os corpos de meninos e meninas, de jovens homens e mulheres".

Esta perspectiva de controle do corpo, para atingir fins estabelecidos por estereótipos do sistema sócio-econômico vigente pode ser observada para legitimar a atuação da Educação Física em diversos contextos, como por exemplo: em academias de ginástica e musculação onde busca-se atingir ideais de beleza, no treinamento desportivo através do disciplinamento de corpos para o máximo rendimento técnico e físico e, também não se exclui aqui o âmbito da Educação Física escolar no que tange a contribuir com uma perspectiva funcionalista de sociedade. Apresentar subsídios teóricos para a Educação Física, sob a uma visão de corporeidade ou de ser humano compreendido na perspectiva de totalidade com os elementos da natureza e da sociedade é objetivo deste estudo.

Para tanto, faz-se necessário compreender algumas bases estruturais do atual sistema sócio-econômico vigente e sua relação com a formação dos sujeitos. Compreender alguns aspectos que dizem respeito à formação de consciências bem como a constituição da sociedade e, apontar alguns encaminhamentos para as práticas da Educação Física é tema de reflexão ao longo deste estudo.

\section{A (INTER)AÇÃO DO CORPO, DA CULTURA E DA NATUREZA}

Inicialmente faz-se necessário buscar entendimento de algumas questões cruciais para este estudo, partindo da tentativa em compreender como se constitui o ser humano? Outra indagação coloca-se no questionamento de como se desenvolve as relações sociais em uma comunidade ou instituição na sociedade capitalista? Questões estas que,

\footnotetext{
${ }^{1}$ Em estudo realizado com docentes de um curso de graduação em Educação Física, CHERUBIN, A. S.; VIEIRA, M. A. Anais do Seminário de iniciação Científica da UNOES, 2004 assinalam que a maioria dos docentes entrevistados possui uma visão dualista e fragmentada de corpo, prevalecendo o corpo biológico e as suas funções fisiológicas como a perspectiva predominante encontrada.

Conexões: revista da Faculdade de Educação Física da UNICAMP, Campinas, v. 10, n. 2, p. 34-48, maio/ago. 201238 ISSN: 1983-9030
} 
por vezes, não são compreendidas conscientemente por não se apresentarem de forma explícita no cotidiano dos sujeitos.

Dirigindo-se de forma sintética e resumida a segunda questão posta em discussão aqui, percebe-se que agindo através da inconsciência ${ }^{2}$ dos sujeitos que algumas instituições regidas pelo modelo de produção do atual sistema sócio-econômico, produzem situações/transações de acordo com o próprio interesse. Duas questões são importantes para o desenvolvimento do atual sistema sócio-econômico: o desconhecimento de todo o processo de produção industrial e tecnológica e, principalmente da falta de ações autônomas em favor da própria categoria. A inconsciência em relação à própria ocupação e/ou da falta de esclarecimento sobre a estrutura organizacional do trabalho, torna as relações de produção como algo "normal" ou dado naturalmente ${ }^{3}$ e, não como produto socialmente produzido pelos sujeitos.

Neste contexto, nas sociedades industriais prevalece, sobretudo, as relações de poder, domínio e de exploração do homem sobre a natureza, bem como, do disciplinamento de corpos a fim de contribuir com a produção de mercadorias para valor de troca e também para valor de uso. Manifesta-se uma perspectiva que tende a substituir de forma inconsciente para os sujeitos, as suas experiências com significado e intencionalidade subjetivas, em favor da objetividade que requer o poder e o lucro. De acordo com Gooldmann, $4: 125$

[...] a economia capitalista tende a substituir na consciência dos produtores o valor de uso pelo valor de troca e as relações humanas concretas e significativas por relações abstratas e universais entre vendedores e compradores; tende assim a substituir no conjunto da vida humana, o qualitativo pelo quantitativo.

A partir desta compreensão, destaca-se a fragmentação do processo mercadológico o qual, constitui-se sob uma tradição reducionista e de funcionalidade social, separando os

\footnotetext{
${ }^{2}$ Busca-se compreender "inconsciência" em Fromm ${ }^{9}$ o qual assinala que inconsciente significa não ver, estar cego do que existe dentro ou fora de nós.

${ }^{3}$ Embora um tanto longo, é interessante aqui apresentar um trecho de "A Reificação" no intuito de esclarecer com mais detalhe o problema da inconsciência humana, como segue: “Um par de sapatos custa cinco mil francos'. É a expressão de uma relação social implicitadamente humana entre o criador de gado, o curtidor de couro, seus operários, seus empregados, o revendedor, o negociante de sapatos e, finalmente o último, o consumidor. Mas nada disso é visível; a maioria desses personagens não se conhece e até ignoram sua existência mutuamente. Ficariam todos espantados de saber da existência de um laço que os une. Tudo isso se exprime por um só fato: 'um par de sapatos custa cinco mil francos"," 4:122

Conexões: revista da Faculdade de Educação Física da UNICAMP, Campinas, v. 10, n. 2, p. 34-48, maio/ago. 201239 ISSN: 1983-9030
} 
"corpos produtivos" de seus produtos, desenvolvendo assim, na sociedade industrial uma cultura de exploração dos recursos físicos, naturais e dos próprios sujeitos, em favor do desenvolvimento comercial. Assim, toda a produção desenvolvida pelo corpo, ou pelos disciplinados corpos dos operários, transformam-se em uma "soma" que produz lucro, eis então, a reificação do trabalho corporal humano.

Esta perspectiva de trato com o corpo e com a natureza estão enraizadas e fundamentadas em um pensamento centrado na individualidade da filosofia da consciência, a qual mantém enrijecida a relação dualista, sujeito-objeto. Neste âmbito, revela-se, principalmente, a crença e a confiança em um padrão de racionalidade instrumental, o qual torna possível manipular e dominar a natureza e o próprio ser humano em favor do desenvolvimento científico e tecnológico. Fensterseifer ${ }^{5: 65}$ cita que nesta relação,

Sujeito e objeto são então 'des-qualificados', tornados pura abstração, sujeito livre dos sentidos e paixões, objeto destituído de cultura e história, consideradas fontes de engano e ilusões. O que os liga é a racionalidade comum a ambos, fonte de objetividade do conhecimento.

Entretanto, sob o ponto de vista fenomenológico de compreender as relações de corpo e mundo e/ou ser humano e sociedade, apresenta-se uma ótica em que não há uma separação entre ser humano e mundo, mas, sobretudo, um ser humano que constrói seu mundo da vida na medida em que se constitui mutuamente com os outros, desenvolvendo e transformando o contexto sócio-cultural. Neste sentido, Trebells, ${ }^{6: 40}$ destaca que

[...] os esclarecimentos que separam substancialmente pessoa/sujeito de um lado e mudo/objeto de outro, porque isso pode se manifestar como desenvolvimento secundário que, por sua vez, baseia-se numa antecedência de uma unidade primordial.

Sob esta visão, o mundo, os objetos físicos e os fenômenos naturais perdem sua passividade no momento em que os sujeitos agem de forma subjetiva e intencional com os mesmos, ou seja, o corpo age de forma relacional e indissociável como o mundo.

Esta maneira dialógica de compreender as interações entre seres humanos e o mundo demonstra explicitadamente uma questão de reciprocidade entre ambos na constituição do corpo, da natureza e da cultura. De acordo com Merleau-Ponty ${ }^{7}$ é na relação com o Conexões: revista da Faculdade de Educação Física da UNICAMP, Campinas, v. 10, n. 2, p. 34-48, maio/ago. 201240 ISSN: 1983-9030 
outro que podemos nos abrir para o mundo, perceber que a presença deste outro em mim e, ao mesmo tempo, ver-me limitado por ele, abrindo assim uma possibilidade de me singularizar em meio a tantas outras. Isso significa compreender que as relações constituídas socialmente entre os seres humanos desenvolvem-se de forma intersubjetiva na dependência, na limitação e nas possibilidades das experiências presentes em diferentes contextos, quais sejam: no mundo da vida ou no mundo do trabalho.

Percebe-se então, que sob esta perspectiva holística as atitudes dos sujeitos em relação aos outros sujeitos e aos demais elementos "naturais", desencadeiam em valores semeados que posteriormente serão colhidas de uma ou de outra forma, na mesma intensidade em que foram "plantados".

\section{“EDUCANDO" CORPOS}

Em se tratando especificamente da primeira questão apresentada neste estudo, torna-se complexo expor de forma precisa e explicitadamente como se constitui o ser humano, em virtude das múltiplas possibilidades de compreensão, e de teorias que as fundamentam. Porém, algumas considerações podem ser apresentadas neste curto espaço e, assim, contribuir para a atuação da Educação Física enquanto prática pedagógica que intervém na formação dos sujeitos. Busca-se então, uma compreensão para esta questão em $\mathrm{Kant}^{8}$ o qual afirma que "[...] o homem é o que a educação faz dele". Educação é entendida aqui no sentido latu da expressão, ou seja, o ser humano se constitui por meio das possibilidades oferecidas no contexto sócio-cultural e trilhadas por si próprio, compreendendo-se então, os espaços da educação formal e as demais interações sociais do mundo de vida.

Assim sendo, pode se afirmar que o homem torna-se "humano" através das experiências vivenciadas "conscientemente" e, socialmente proporcionadas por instituições como, por exemplo, a família, a escola, grupos sindicais, e demais experiências vividas informalmente. Fromm" 9:127 assinala que a consciência humana "[...] significa temos conhecimento da realidade dentro ou fora de nós mesmos" função esta que permite a sobrevivência e adaptação ao ambiente sócio-cultural. Dessa forma, pode-se afirmar que a consciência humana é proporcionada pela percepção da realidade - sendo adquirida Conexões: revista da Faculdade de Educação Física da UNICAMP, Campinas, v. 10, n. 2, p. 34-48, maio/ago. 201241 ISSN: 1983-9030 
por meio dos sentidos: visão, audição, olfato, entre outros - e condicionada pelas experiências que os seres humanos obtém ao longo da vida. Fromm ${ }^{9}$ considera ainda alguns elementos que denomina de filtro social, ${ }^{4}$ os quais evitam que muitas experiências tornam-se conscientes aos seres humanos, e que produzem certa "inconsciência social".

Em meio às instâncias formadoras do filtro social, encontra-se na sociedade uma instituição que tem por excelência transmitir os saberes sistematizados e acumulados historicamente, a qual intervém diretamente na formação dos sujeitos, obviamente menciona-se neste contexto a escola. Sendo assim, no conjunto de seus componentes curriculares a escola age intencionalmente e formalmente na formação dos sujeitos. De acordo com o art. $2^{\circ}$ da LDB 9.394/96 (Lei de Diretrizes e Bases da Educação) a educação tem por finalidade "[...] o pleno desenvolvimento do educando, seu preparo para o exercício da cidadania e sua qualificação para o trabalho". ${ }^{10}$ Neste sentido, as ações educativas legalmente caminham na direção do exercício da "cidadania" - não especificando em qual dimensão se trata esta cidadania - e a qualificação dos sujeitos para o mercado de trabalho, ou seja, traduz-se numa perspectiva para o bom funcionamento da sociedade e, assim manter a "Ordem e o Progresso".

Percebe-se dessa forma que, por muitas vezes, as instituições de educação através de métodos de ensino que buscam o melhor desempenho e aproveitamento no vestibular entre outros exames, contribuem para a formação de consciências ofuscadas, despertando nos sujeitos falsos desejos, falsos interesses e falsas necessidades. Adorno $^{11: 141}$ apresenta sua compreensão inicial de educação, na qual destaca:

Evidente não a assim chamada modelagem de pessoas, porque não temos o direito de modelar pessoas a partir do seu exterior; mas não a mera transmissão de conhecimentos, cuja característica de coisa morta já foi mais do que destacada, mas a produção de uma consciência verdadeira.

Contribuir para a produção de uma consciência verdadeira, no âmbito escolar significa proporcionar elementos pedagógicos em que, pelo quais, apresentam-se experiências

\footnotetext{
${ }^{4}$ Para maior compreensão, Fromm ${ }^{9}$ considera os elementos Linguagem, Lógica e os Tabus sociais, como produtos do modo de vida de uma sociedade, que restringe a formação de experiências significativas aos sujeitos.
}

Conexões: revista da Faculdade de Educação Física da UNICAMP, Campinas, v. 10, n. 2, p. 34-48, maio/ago. 201242 ISSN: 1983-9030 
que façam sentido e significado ao contexto em que os alunos atuam. Destaca-se também aqui, a intenção da educação contribuir na orientação dos sujeitos/alunos para a atuação crítica e reflexiva quanto às estruturas sociais e, sendo assim, agir de forma autônoma e esclarecida em sua inserção e na constituição do contexto sócio-cultural no qual vivem.

Considerando este elemento apresentado por Adorno, ${ }^{11}$ as práticas pedagógicas da Educação Física juntamente com os inúmeros elementos da cultura de movimento, podem contribuir com a ampliação e conseqüente maior variedade de experiências de movimento. Nestes termos, pode-se contribuir no desenvolvimento dos aspectos técnicos, das habilidades motoras e capacidades físicas, mas, sobretudo, também auxiliar juntamente com as demais instâncias escolares no desenvolvimento de competências sociais como: autonomia, solidariedade, cooperação, argumentação crítica, entre outras. Este sentido de formação humana busca contribuir com o esclarecimento quanto as estruturas sociais, através reflexão crítica proporcionada em práticas da Educação Física escolar. Assim sendo, alguns elementos da especificidade da Educação Física podem ser "estudados" e refletido criticamente como Pires, ${ }^{12: 105}$ destaca:

[...] os conceitos idealizados de saúde, corpo e beleza, implícitos na oferta de revistas e programas de ginástica na TV, e de máquinas e aparelhos para a exercitação física a domicílio, explicitam uma concepção funcionalista de sociedade, fundada no individualismo e orientada a fins racionais estáticos. Entendidos como filtros ideológicos que se interpõem e redirecionam a relação entre sujeito e realidade.

Isto obviamente requer certa re-organização, planejamento e até qualificação de algumas práticas da Educação Física escolar, no sentido de superar os "modismos" fortemente influenciados por modalidades esportivas que encontram-se em destaque na mídia e, também, ultrapassar o exagerado hábito de improvisação e a dependência do "senso de humor" dos profissionais em suas práticas de ensino. Neste sentido, busca-se, sobretudo, deter o foco nas experiências de movimento dos sujeitos, contribuindo para que as práticas de ensino sejam permeadas por momentos de ação e reflexão, mediadas pela comunicação recíproca entre alunos/alunos, professor/alunos sobre o fenômeno estudado. 
Destaca-se neste contexto, um importante fator que pode contribuir com as práticas de ensino da Educação Física, a comunicação verbal sobre o fenômeno estudado. A comunicação verbal pode ser considerada como o melhor nível de expressão de um determinado conhecimento e de compreensão sobre determinado assunto, bem como, a mesma desencadeia em processos reflexivos, pois, ao se comunicar verbalmente com os outros os sujeitos desenvolvem o pensamento crítico e a conscientização sobre o estudado. Em se tratando da consciência, Adorno ${ }^{11: 151}$ destaca ainda que:

[...] a consciência é o pensar em relação à realidade, ao conteúdo ---a relação entre as formas e estruturas de pensamento de sujeito e aquilo que este não é. Este sentido mais profundo da consciência ou faculdade de pensar não é apenas o desenvolvimento lógico formal, mas ele corresponde literalmente a capacidade de fazer experiências. Eu diria que pensar é o mesmo que fazer experiências intelectuais. Nesta medida e nos termos que procuramos expor, a educação para a experiência é idêntica a educação para a emancipação.

Por meio de suas ações didático-pedagogicas que a Educação Física pode contribuir intencionalmente enquanto componente curricular, no sentido de promover experiências "intelectuais" e de movimento que façam sentido e significado aos sujeitos/alunos demonstrando assim, a condição de ser humano que tem a possibilidade de construir a sociedade, produzir cultura e adaptar-se e modificar continuamente diferentes situações. Destaca-se nesta perspectiva a compreensão de "inacabamento" do ser humano que Freire, ${ }^{13: 53}$ assinala: "[...] inacabado, sei que sou um ser condicionado mas, consciente do inacabamento, sei que posso ir mais além dele. Esta é a diferença profunda entre o ser condicionado e o ser determinado".

Apostar no "inacabamento" do ser humano é acreditar na possibilidade de construção de uma sociedade mais justa e humana, porém, para isto, faz-se necessário a conscientização da real situação na qual se está inserido, para então, agir esclarecidamente e com autonomia de forma contínua nas situações do cotidiano, contribuindo assim para o desenvolvimento de uma sociedade emancipada.

\section{CONSIDERAÇÕES FINAIS}

Destaca-se neste ensaio teórico principalmente a questão de dois conceitos fundamentais para a formação humana e a constituição social. "Consciência" e 
"experiência", pelos quais pode haver possibilidade do ser humano constituir-se na posição de "autor" que produz cultura através da interação social, determinando também na sua forma de agir, tratar e intervir na natureza. Embora dois termos distintos quando se trata do significado literal das palavras, experiência e consciência estão intimamente imbricadas e dependentes uma do outra. As inúmeras experiências que um ser humano adquire ao longo de sua vida são importantes para o seu modo de viver e de sobreviver e, determinante para o conhecimento, compreensão e esclarecimento de fatos, de conceitos, oferecendo a condição de realizar uma leitura crítica da realidade presente no contexto sócio-cultural em que o sujeito se insere.

Entretanto, devido ao extremo modo de vida produtivo nas sociedades contemporâneas, as experiências dos sujeitos em sua maioria 5 são produzidas de forma "artificial", ou seja, as mesmas são transferidas aos sujeitos de forma superficial com a finalidade de atender, sobretudo, aos ditames do sistema sócio-econômico vigente. Um dos fatores que contribuíram para o desaparecimento de experiências constituídas subjetivamente, pode ser atribuído a crescente urbanização das cidades, que por consequiência diminuiu os espaços do mundo da vida dos sujeitos, substituindo-os por edifícios, shopping centers, e demais espaços padronizados que são destinados à área de lazer e para a prática esportiva.

Por meio da "regulamentação de experiências" constitui-se uma cultura que submete os corpos a serem bem ajustados aos interesses das estruturas dominantes, as quais, também produzem desejos que substituem as reais necessidades dos sujeitos, pela ansiedade e busca no consumismo. Dessa forma, algumas instâncias contribuem para a formação de uma espécie de "pseudo-experiência", as quais auxiliam na formação de consciências ofuscadas e determinadas a agirem de acordo com a estrutura social dominante.

Encontra-se neste âmbito uma importante contribuição para educação formal, no sentido de proporcionar processos de ensinar e aprender através de experiências que contribuam

\footnotetext{
${ }^{5}$ Fromm $^{9}$ considera-se que as assinala que $90 \%$ do que preenche nossas consciências não são reais e que grande parte do "verdadeiramente real" não é consciente.

Conexões: revista da Faculdade de Educação Física da UNICAMP, Campinas, v. 10, n. 2, p. 34-48, maio/ago. 201245 ISSN: 1983-9030
} 
com a percepção da realidade na qual, os sujeitos se atuam. Apresenta-se então, experiência a partir do que Maraun ${ }^{14: 191}$ atribui:

Experiência não é algo que se pode, simplesmente, transmitir ou transferir para outro. É necessário que a gente mesmo esteja inteiramente envolvida numa sequiência de acontecimentos para que algo de significativo, para a pessoa, possa se experimentado.

Assim sendo, as práticas de ensino podem ser desenvolvidas através de experiências que façam sentido aos sujeitos, permitindo a compreensão das estruturas sócio-culturais.

Nestes termos, apresenta-se a compreensão de processos de ensinar e aprender a partir de uma perspectiva que amplie a questão do saber-fazer técnica e eficientemente, para o saber-sentir conscientemente, motivando principalmente a curiosidade em relação ao fenômeno estudado. Para tanto, faz-se necessário proporcionar procedimentos didáticometodológicos que valorizem as experiências subjetivas dos sujeitos/alunos oriundas do mundo da vida, problematizando-as de forma dialógica e recíproca com demais saberes sistematizados historicamente. Apresenta-se para as práticas pedagógicas uma alternativa que amplia os tradicionais métodos de produzir hierarquicamente conhecimentos de forma mecânica e transversal, priorizando as experiências dos sujeitos através da interlocução de saberes, a qual Marques, ${ }^{15: 86}$ assinala que os,

[...] saberes constituídos em anterioridade, prévios as relações com que se vão reconstruir enquanto aprendizagem, não mera repetição ou cópia, mas efetiva reconstrução enquanto desmontagem e recuperação de modo novo na perspectiva do diálogo dos interlocutores constituídos em comunidade de livre-conversação e de argumentação.

As ações educativas desenvolvidas sob esta perspectiva apontam para a compreensão de que os conhecimentos produzidos historicamente podem apresentar uma conexão direta e que faça sentido aos saberes adquiridos pelas experiências do mundo da vida dos sujeitos. Para isto, faz-se necessário destacar, sobretudo, uma concepção básica e fundamental para a educação: sujeito e objeto, ser humano e mundo, mente e corpo são vistos de forma indissociável constituindo-se, transformando-se e estendendo-se em meio a cultura.

\section{REFERÊNCIAS}

Conexões: revista da Faculdade de Educação Física da UNICAMP, Campinas, v. 10, n. 2, p. 34-48, maio/ago. 201246 ISSN: 1983-9030 
${ }^{1}$ SANTIN, S. O corpo simplesmente corpo. Movimento, Porto Alegre, v. 1, n.15, p. 5773, 2001.

${ }^{2}$ FREITAS, G. G. O esquema corporal, a imagem corporal, a consciência corporal e a corporeidade. Ijuí: Ed. da Unijuí. 1999.

${ }^{3}$ LOURO, G. L. Corpo, escola e identidade. Revista Educação e Realidade, Porto Alegre, v. 25, n. 2, p. 59-76, 2000.

${ }^{4}$ GOOLDMANN, L. Dialética e cultura. Rio de Janeiro, Paz e Terra, 1979.

${ }^{5}$ FENSTERSEIFER, P. E. A Educação Física na crise da modernidade. Ijuí: Ed. da Unijuí, 2001.

${ }^{6}$ TREBELS, A. H. A concepção dialógica do movimento humano: uma teoria do "semovimentar". In: KUNZ, E.; TREBELS, A. H. Educação Física críticoemancipatória: com uma perspectiva alemã do esporte. Ijuí: Ed. da Unijuí, 2006.

${ }^{7}$ MERLEAU-PONTY, M. O visível e invisível. São Paulo: Perspectiva, 2000.

${ }^{8}$ KANT, I. Crítica da razão pura. 2. ed. São Paulo: Abril Cultural, 1983. (Os Pensadores).

${ }^{9}$ FROMM, E. Consciência e sociedade industrial. In: FORACCHI, M.; MARTINS, J. S. Sociologia e sociedade. Rio de Janeiro: Livros Técnicos e Científicos, 1977.

${ }^{10}$ BRASIL. Ministério da Educação e Cultura. Lei de diretrizes e bases da educação. Disponível em: http://portal.mec.gov.br/arquivos/pdf/ldb.pdf, Brasilia, 1996. Acesso em: 19 fev. 2008.

${ }^{11}$ ADORNO, T. Educação e emancipação. 3. ed. São Paulo: Paz e Terra, 1995.

Conexões: revista da Faculdade de Educação Física da UNICAMP, Campinas, v. 10, n. 2, p. 34-48, maio/ago. 201247 ISSN: 1983-9030 
${ }^{12}$ PIRES, G. L. Educação Física e o discurso midiático: abordagem críticoemancipatória. Ijuí: Ed. da Unijuí, 2002.

${ }^{13}$ FREIRE, P. Pedagogia da autonomia: saberes necessários a prática educativa. São Paulo: Paz e Terra, 1996.

${ }^{14}$ MARAUN, H.-K. Ensino-aprendizagem aberto às experiências: sobre a gênese e estrutura da aprendizagem autodetermina na Educação Física. In: KUNZ, E.; TREBELS, A. H. Educação Física crítico-emancipatória: com uma perspectiva alemã do esporte. Ijuí: Ed. da Unijuí, 2006.

${ }^{15}$ MARQUES, M. O. Educação/interlocução, aprendizagem/reconstrução de saberes. Ijuí: Ed. da Unijuí, 1996.

Recebido em: 06 março 2012. Aceito em: 13 junho 2012. 